\title{
Correction to: Release of an enantioselective nitrilase from Alcaligenes faecalis MTCC 126: a comparative study
}

\author{
Renu Singh $^{1} \cdot$ Anirban Banerjee $^{1} \cdot$ Praveen Kaul $^{1} \cdot$ Brajesh Barse $^{1} \cdot$ U. C. Banerjee ${ }^{1}$
}

Published online: 24 February 2018

c) Springer-Verlag GmbH Germany, part of Springer Nature 2018

\section{Correction to: Bioprocess Biosyst Eng (2005) 27: 415-424 https://doi.org/10.1007/s00449-005-0013-4}

In the original version of our paper entitled "Release of an enantioselective nitrilase from Alcaligenes faecalis MTCC 126: a comparative study" (2005) 27:415-424, some references to already published articles were inadvertently left out.

1. Under the Introduction section, in the second paragraph of page 415, the claim: "the enzyme was purified to homogeneity and found to have a sub-unit of molecular weight of $32 \mathrm{kDa}$ " should be supported with the published article by Yamamoto K, Fujimatsu I, Komatsu K. "Purification and Characterization of the Nitrilase from Alcaligenes faecalis ATCC 8750 Responsible for Enantioselective Hydrolysis of Mandelonitrile”, Journal of Fermentation and Bioengineering (1992), 73(6), 425-430.

2. The procedure described in the paragraph of "High performance liquid chromatography" under the Materials and Methods section was conducted according to the Reference [2] of the original version of our paper (Banerjee A, Kaul P, Sharma R, Banerjee UC, "A highthroughput amenable colorimetric assay for enantioselective screening of nitrilase producing microorganisms using $\mathrm{pH}$ sensitive indicators". J Biomol Screen, 2003, 8:559-565).

3. In the paragraph "Microorganism and cultivation conditions" under the Materials and methods section, page 416, the media composition should be referred to Reference [10] from the original version of our paper (Yamamoto K, Oishi K, Fujimatsu I, Komatsu K (1991) Production of (R)-(-)-mandelic acid from mandelonitrile by Alcaligenes faecalis ATCC 8750. Appl Environ Microbiol 57:3028-3032)).

4. In the paragraph "Nitrilase purification" under the Materials and methods section, page 417, the following reference should be included: Yamamoto K, Fujimatsu I, Komatsu K., "Purification and Characterization of the Nitrilase from Alcaligenes faecalis ATCC 8750 Responsible for Enantioselective Hydrolysis of Mandelonitrile", Journal of Fermentation and Bioengineering (1992), 73(6), 425-430.

5. In the paragraph "Sample preparation for high performance liquid chromatography (HPLC)" under the Materials and methods section, page 417, the Reference [10] from the original version of our paper should be included (Yamamoto K, Oishi K, Fujimatsu I, Komatsu K (1991) Production of (R)-()-mandelic acid from mandelonitrile by Alcaligenes faecalis ATCC 8750. Appl Environ Microbiol 57:3028-3032)).

The following reference was missing in the original version of our paper:

Yamamoto K, Fujimatsu I, Komatsu K (1992) Purification and characterization of the nitrilase from Alcaligenes faecalis ATCC 8750 responsible for enantioselective hydrolysis of mandelonitrile. J Ferment Bioeng 73(6):425-430.

The original article can be found online at https://doi.org/10.1007/ s00449-005-0013-4.

\footnotetext{
U. C. Banerjee

ucbanerjee@niper.ac.in

1 Department of Pharmaceutical Technology, National Institute of Pharmaceutical Education and Research, Sector-67, SAS Nagar, Punjab 160 062, India
} 